Copyright $(C) 2019$ by the author(s). Published here under license by the Resilience Alliance.

Oberlack, C., D. Sietz, E. Bürgi Bonanomi, A. De Bremond, J. Dell'Angelo, K. Eisenack, E. C. Ellis, G. Epstein, M. Giger, A.

Heinimann, C. Kimmich, M. T. J. Kok, D. Manuel-Navarrete, P. Messerli, P. Meyfroidt, T. Václavík, and S. Villamayor-Tomas. 2019.

Archetype analysis in sustainability research: meanings, motivations, and evidence-based policy making. Ecology and Society $24(2): 26$.

https://doi.org/10.5751/ES-10747-240226

Synthesis, part of a Special Feature on Archetype Analysis in Sustainability Research

\title{
Archetype analysis in sustainability research: meanings, motivations, and evidence-based policy making
}

\author{
Christoph Oberlack $^{1,2}, \underline{\text { Diana Sietz }}^{3,4}$ Elisabeth Bürgi Bonanomi $^{2}$, Ariane de Bremond $^{2,5,6}$ Jampel Dell'Angelo $^{7}, \underline{\text { Klaus Eisenack }}^{8}$,

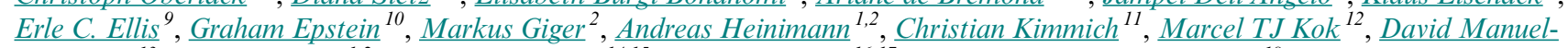 \\ Navarrete $^{13}, \underline{\text { Peter Messerli }}^{1,2}, \underline{\text { Patrick Mevfroidt }}^{14,15}$, Tomáš Václavík $^{16,17}$ and Sergio Villamayor-Tomas $^{18}$
}

\begin{abstract}
Archetypes are increasingly used as a methodological approach to understand recurrent patterns in variables and processes that shape the sustainability of social-ecological systems. The rapid growth and diversification of archetype analyses has generated variations, inconsistencies, and confusion about the meanings, potential, and limitations of archetypes. Based on a systematic review, a survey, and a workshop series, we provide a consolidated perspective on the core features and diverse meanings of archetype analysis in sustainability research, the motivations behind it, and its policy relevance. We identify three core features of archetype analysis: recurrent patterns, multiple models, and intermediate abstraction. Two gradients help to apprehend the variety of meanings of archetype analysis that sustainability researchers have developed: (1) understanding archetypes as building blocks or as case typologies and (2) using archetypes for pattern recognition, diagnosis, or scenario development. We demonstrate how archetype analysis has been used to synthesize results from case studies, bridge the gap between global narratives and local realities, foster methodological interplay, and transfer knowledge about sustainability strategies across cases. We also critically examine the potential and limitations of archetype analysis in supporting evidence-based policy making through context-sensitive generalizations with case-level empirical validity. Finally, we identify future priorities, with a view to leveraging the full potential of archetype analysis for supporting sustainable development.
\end{abstract}

Key Words: archetype; land systems; social-ecological system; sustainability; vulnerability

\section{INTRODUCTION}

Unprecedented rates of social-environmental change and the urgent need to design effective strategies for sustainable development are driving demand for efforts to scale up case-based knowledge (Cox 2014, Verburg et al. 2015), but in contextsensitive ways (Ostrom 2007, Magliocca et al. 2018). Archetypes are increasingly used as a methodological approach to understand recurrent patterns of variables and processes that shape the sustainability of social-ecological systems in different locations and at different times (e.g., Jäger et al. 2007, Messerli et al. 2016, Sietz et al. 2017, Levers et al. 2018; Eisenack et al. unpublished manuscript, http://citeseerx.ist.psu.edu/viewdoc/download? $\underline{\text { doi }=10.1 .1 .572 .4210 \& r e p=r e p 1 \& t y p e=p d f}$ ). The approach supports contextually explicit generalizations of results from case studies. It facilitates the transfer of knowledge from one case to another, thereby identifying the contextual and normative conditions under which particular strategies effectively support sustainable development.

The history of archetypes thinking dates back as far as the ancient philosophy of Plato and the philosophy of Locke, with archetypes being understood as original forms of complex, real things (Locke 1690). In psychology, Jung (1959) developed psychological archetypes as patterns and symbols of the collective unconscious, which are expressed in dreams and human imagination. A major origin of contemporary archetype analysis in sustainability research is the concept of system archetypes in the field of system dynamics. System archetypes characterize generic structures and behaviors of systems (Senge 1990, Wolstenholme 2003, 2004). Usually depicted as causal graphs, they represent typical causal linkages that reappear across many cases such as the tragedy of the commons or limits to growth (Braun 2002, Bennett et al. 2005, Lane 2008).

Archetypes are analyzed for an increasing range of topics in sustainability research, including land systems, governance and institutional change, social-ecological systems, and global change (Eisenack et al. 2019; Sietz, Frey, Roggero, et al. unpublished manuscript). For example, "archetypes of vulnerability" depict recurrent configurations of factors that generate vulnerability to socioeconomic and ecological change at global, regional, and local scales (Jäger et al. 2007, Vidal Merino et al. 2019). "Land system archetypes" represent patterns of land-use intensity, environmental conditions, and socioeconomic factors that appear repeatedly across the terrestrial earth surface (Václavík et al. 2013, Levers et al. 2018). "Archetypes of livelihood vulnerability and sustainability" synthesize the factors and processes explaining how large-scale land acquisitions affect rural livelihoods (Oberlack et al. 2016).

\footnotetext{
${ }^{1}$ Institute of Geography, University of Bern, Bern, Switzerland, ${ }^{2}$ Centre for Development and Environment (CDE), University of Bern, Bern, Switzerland, ${ }^{3}$ Potsdam Institute for Climate Impact Research, Member of the Leibniz Association, P.O. Box 60 12 03, D-14412 Potsdam, Germany, ${ }^{4}$ Wageningen University, Wageningen, The Netherlands, ${ }^{5}$ Global Land Programme, ${ }^{6}$ Geographical Sciences Department, University of Maryland, College Park, Maryland, USA, ${ }^{7}$ Department of Environmental Policy Analysis, Institute for Environmental Studies, VU University Amsterdam, Amsterdam, The Netherlands, ${ }^{8}$ Resource Economics Group, Humboldt Universität zu Berlin, Germany, ${ }^{9}$ Department of Geography and Environmental Systems, University of Maryland, Baltimore, Maryland, USA, ${ }^{10}$ Environmental Change and Governance Group, School of Environment, Resources and Sustainability, University of Waterloo, Waterloo, Ontario, Canada, ${ }^{11}$ Department of Environmental Studies, Masaryk University, Brno, Czechia, ${ }^{12}$ PBL Netherlands Environmental Assessment Agency, The Hague, The Netherlands, ${ }^{13}$ School of Sustainability, Arizona State University, Tempe, Arizona, USA, ${ }^{14}$ Georges Lemaître Center for Earth and Climate Research, Earth and Life Institute, UCLouvain, Louvainla-Neuve, Belgium, ${ }^{15}$ F.R.S.-FNRS, Brussels, Belgium, ${ }^{16}$ Palacký University Olomouc, Department of Ecology and Environmental Sciences, Olomouc, Czechia, ${ }^{17}$ UFZ - Helmholtz Centre for Environmental Research, Department of Computational Landscape Ecology, Leipzig, Germany, ${ }^{18}$ Institute of Environmental Science and Technology (ICTA), Autonomous University of Barcelona, Barcelona, Spain
} 
Fig. 1. Varieties of archetype analysis in sustainability research based on a systematic literature review. (A) Qualitative, quantitative, or mixed methods. (B) Empirical or nonempirical methods. (C) Scale of knowledge chain.

(a) Methodology: qualitative, quantitative, or mixed

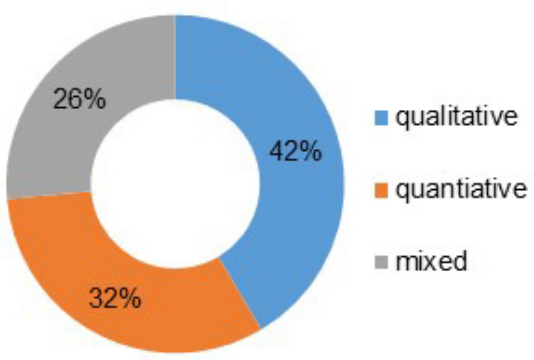

(b) Methodology: empirical or non-empirical

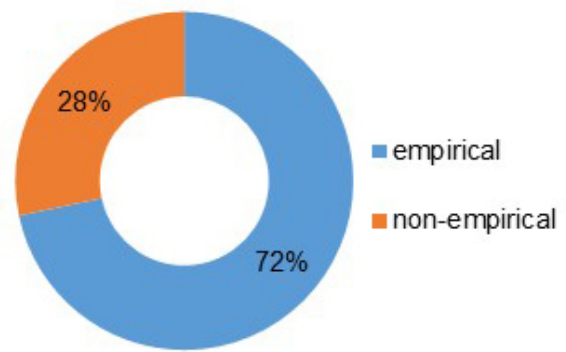

(c) Scale of knowledge claim

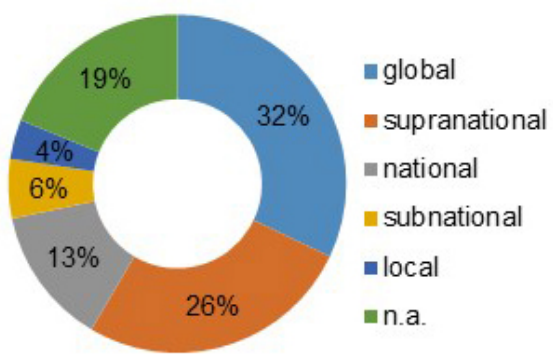

Archetype analysis in sustainability research has proliferated considerably since 2013. This rapid growth and diversification has generated variations, inconsistencies, and confusion about the meanings, potentials, and limitations of archetypes. We therefore provide a consolidated perspective on the core features and diverse meanings of archetype analysis, its underlying motivation, and its relevance to policy, with a focus on sustainability research. Archetype analyses in other fields, including psychology (Jung 1959) and literature studies (Kugler 1982), are beyond the scope of our work.

After describing our methods and the state of the literature, we clarify the core features of archetype analysis in sustainability research and provide guidelines for understanding multiple meanings of archetypes. Subsequently, we show what motivates researchers to use archetype analysis as they tackle six knowledge problems that persistently challenge sustainability research, policy making, and practice. Next, we examine the potentials of archetype analysis in supporting evidence-based, contextsensitive policy making, and we discuss limitations. Finally, we identify future priorities, with a view toward leveraging the full potential of archetype analysis for supporting sustainable development.

\section{METHODS}

This work is based on a survey, two research workshops, and a systematic review of the scientific literature on archetypes. The survey compiled the perspectives and experiences of users of the archetypes approach regarding key topics in archetype analysis, main potentials and challenges of archetype analysis, and suitable methods. We distributed the survey in March 2017 to the 28 participants of the first research workshop; 17 completed surveys were returned (response rate: $60.7 \%$ ). We analyzed the responses by synthesizing the main themes for each question. The survey results informed the debates at the first workshop, the coding scheme for the systematic review, and the descriptions of meanings, motivations, and policy relevance.

The two research workshops were held at the University of Bern, Switzerland, in May 2017 and at the Humboldt Universität zu Berlin, Germany, in February 2018. They involved a total of 46 researchers of land systems, institutional analysis, and global change with expertise in archetype analysis based in 12 countries in Europe, Asia, North America, and South America. The workshops synthesized participants' expertise and knowledge in archetype analysis and triggered and showcased cutting-edge applications (Oberlack et al. 2017, Eisenack et al. 2018).

For the systematic literature review, we retrieved peer-reviewed scientific articles from Web of Science and Scopus databases using the keywords (archetyp*) AND ("global change" OR vulnerab* OR sustainab* OR resilien* OR adaptation OR land), yielding 523 documents (final search date: 8 December 2017). Of these artricles, we included papers in our review that: (1) explicitly analyzed archetypes; (2) related to sustainability, vulnerability, land systems, or social-ecological systems; and (3) were peer reviewed. These criteria applied to 45 papers. We added eight eligible papers that were known by the authors but not retrieved through Web of Science or Scopus because four of them are not listed in these databases and four were forthcoming at the time of research. Accordingly, we reviewed 53 papers in total (Appendix 1). This set of papers covered archetype analyses in sustainability research that made explicit reference in the title or abstract to global change, vulnerability, sustainability, resilience, adaptation, or land. Although this set of papers included studies of system archetypes, we do not claim a comprehensive coverage of archetype studies in the field of system dynamics (for overviews, see Sterman 2000, Braun 2002, Wolstenholme 2003, Mirchi et al. 2012). We extracted the following information from the 53 papers: definition of archetypes, number of identified archetypes, motivation to analyze archetypes, focus and unit of analysis, methodology, whether and how the paper analyzes sustainability strategies, scientific discipline, and geographical and temporal scale of analysis. The quantitative and qualitative data gathered informed our debates at the second workshop.

\section{STATE OF THE LITERATURE}

Most papers $(83.0 \%)$ in our sample of 53 were published after 2013 (Appendix 1). The papers document a variety of methods (Fig. 1A), the most frequent of which are meta-analyses of case studies, cluster analyses of spatial data, and system dynamics modeling. Most studies are empirical (Fig. 1B), but some used "archetypes" deductively, for example, to propose conceptual 
frameworks. The majority used archetypes to generate global or supranational knowledge claims (Fig. 1C). Archetypes are analyzed for a wide array of topics and units of analysis, most frequently land systems, water systems, macroeconomic or societal development, agriculture, livelihoods, households, and urban areas.

The number of archetypes identified in the studies ranges widely, from 1 to 32 (mean: 7.0, median: 4.0, standard deviation: 6.5). Studies that use archetypes to identify patterns empirically tend to find a larger number of archetypes $(9.5,6.0,8.2)$ than studies that use archetypes for diagnosis $(6.1,4.0,4.1)$ or for scenario development $(3.8,4.0,1.3)$.

\section{ARCHETYPE ANALYSIS IN SUSTAINABILITY RESEARCH: CORE FEATURES, DIVERSE MEANINGS, AND RELATED APPROACHES}

\section{Core features of archetype analysis in sustainability research}

We identified three core features of archetype analysis in sustainability research. Archetype analysis investigates recurrent patterns of the phenomenon of interest at an intermediate level of abstraction to identify multiple models that explain the phenomenon under particular conditions.

\section{Recurrent patterns}

Archetypes are recurrent patterns that hold across cases of the phenomenon of interest, meaning that an archetype reappears in more than one case (Eisenack 2012). Accordingly, archetype analyses do not adopt research designs of single case studies. Instead, typical methods include meta-analyses of case studies (Messerli et al. 2016, Oberlack et al. 2016), statistical analyses (Václavík et al. 2013, Sietz et al. 2017), system dynamics modeling (Banson et al. 2016), and participatory scenario development (Wardropper et al. 2016), among others. For a detailed assessment of the methodological portfolio, see Sietz, Frey, Roggero, et al. unpublished manuscript.

Preconditions for archetype analysis are that multiple cases are sufficiently similar in the defining features of the considered phenomenon (e.g., large-scale land acquisitions, climate change adaptation) and the cases share some attributes (e.g., variables and causal mechanisms) that are similar in qualitative or quantitative terms. Every case of a phenomenon is unique in some aspects if it is described in sufficient detail (Poteete and Ostrom 2008). However, cases typically share similarities in particular attributes (Ostrom 2009). Archetype analysis identifies those configurations of attributes that are shared across a set of cases and are crucial for describing the system dynamics or causal effect of interest.

\section{Multiple models}

A second core feature of archetype analysis is the assumption that capturing the diversity of contexts, processes, and outcomes of a phenomenon requires developing multiple models rather than searching for one model that explains all cases of the phenomenon (Young et al. 2006; Eisenack et al. unpublished manuscript, http:// citeseerx.ist.psu.edu/viewdoc/download?doi=10.1.1.572.4210\&rep= rep1\&type $=$ pdf). This approach contrasts with multivariate methods that search for one general model to explain the relationships between independent variables and outcomes.
This feature makes the archetypes approach particularly useful when dealing with heterogeneous sets of cases where there is a need to compare, generalize, or transfer insights across multiple cases. Archetype analysis identifies a suite of archetypes to explain the phenomenon of interest. This approach enables researchers to capture critical details of heterogeneous cases while generalizing across them. The thematic, geographical, and temporal validity of any archetype analysis is enhanced by specifying the particular contextual conditions under which each archetype occurs (Sietz et al. 2012, Magliocca et al. 2018).

\section{Intermediate abstraction}

Attributes of cases in an archetype analysis are described with an intermediate degree of semantic abstraction (Eisenack 2012). Every archetype analysis uses an analytical framework that provides a common vocabulary of attributes to describe the cases. Attributes are formulated in a language that applies to multiple cases, balancing the accuracy and meaning of the attributes (Cox 2008). For instance, the "local elite capture" archetype in Oberlack et al. (2016) is formulated at an intermediate degree of semantic abstraction because the "local elite" concept manifests in different, context-specific ways in different cases: local elites may be chiefs, village headmen or headwomen, elders, or elected state officials, depending on the socio-cultural context of the cases.

Furthermore, abstraction has a second dimension next to the semantic one. Rather than providing a detailed description of one specific case, archetype analysis focuses on essential factors and their associations that explain a phenomenon in multiple cases (Kok et al. 2016). Each archetype usually contains a subset of the attributes depicted in the analytical framework. Depending on the research purpose, this analytical reduction can identify the recurrent factors, processes, and outcomes (Oberlack et al. 2016) or the necessary and sufficient conditions for an outcome (Srinivasan et al. 2012, Kimmich and Villamayor-Tomás 2019).

This core feature of archetypes captures case particularities without risking an "ideographic trap," where the uniqueness of cases is considered incommensurable. If attributes are too specific and overly numerous, every case is indeed different from others. By contrast, if attributes are too abstract, the analysis risks falling into the "nomothetic trap," generalizing to the point of meaninglessness (Petschel-Held 2003, Frey and Cox 2015).

The appropriate degree of abstraction is usually unknown at the beginning of a study. It depends on the research purpose and the methodology (Eisenack et al. 2019). For example, in metaanalyses of case studies, the translation of case study results into the language of the analytical framework during the iterative development of the codebook determines the semantic abstraction of attributes (van Vliet et al. 2016, Dell'Angelo et al. $2017 b$ ). In indicator-based cluster analyses, considerations of hypothesized causal mechanisms and practical considerations of data availability drive semantic abstraction and the selection of attributes (Kok et al. 2016).

The analysis of "nested archetypes," which distinguishes between main archetypes and subarchetypes, makes it possible to incorporate multiple levels of abstraction within one study (Sietz et al. 2017). Similarly, global patterns of vulnerability have been 
refined by focusing on specific regional processes such as those related to smallholder farming in northeast Brazil (Sietz 2014). Overgeneralization can further be prevented by delimiting the scope of a study (Sietz et al. 2012, Magliocca et al. 2018).

\section{Understanding the diversity of meanings of archetypes in sustainability research}

The precise meaning of archetypes varies across studies. The following distinctions help to understand key differences found in the literature on archetypes in sustainability research.

\section{Archetypes as building blocks of cases or typologies of cases}

The most important difference is whether archetypes are identified at the level of building blocks (e.g., causal mechanisms) or at the level of cases. In the building blocks approach, archetypes are identified in such a way that any single case of the phenomenon of interest can be characterized by one or a combination of several archetypes (Eisenack 2012). Each case is characterized by showing which archetypes are present and how they manifest themselves in that particular case. For example, Oberlack et al. (2016) identified archetypical processes that explain how largescale land acquisitions affect rural livelihoods through a modelcentered meta-analysis of case studies. The most important archetypical processes identified were enclosures, elite capture, beneficiary creation, and community-based resistance. The authors identified these archetypes as building blocks, meaning that one or a combination of these processes may operate in a single case of land acquisition. The building blocks approach decomposes each case into distinct components such as processes or causal mechanisms, which may operate simultaneously and together explain the dynamics or outcomes observed in that case. Taking this approach, archetype analysis identifies recurrent patterns at the level of building blocks and the particular conditions and outcomes under which they operate.

By contrast, when archetypes are identified at the level of cases, they are identified in such a way that each case is categorized by exactly one archetype. For example, Václavík et al. (2013) and Levers et al. (2018) used self-organizing maps to identify land system archetypes based on similarities of land systems in terms of land-use intensity, social-ecological conditions, and landchange trajectories. The archetypes in these studies were identified by a data-driven sensitivity analysis that minimized variability of cases within archetypes and maximized variability between them. Other cluster analyses determined archetypes based on the stability of cluster partitions (Kok et al. 2016, Sietz et al. 2017).

The main difference between the two approaches is the level at which similarities across cases are identified: Similarities of processes or causal mechanisms that explain the phenomenon of interest (building blocks) or similarities of entire cases of that phenomenon (case typology). In set-theoretic terms, the building blocks approach allows subsets of cases to which certain archetypical configurations of attributes apply to intersect (Oberlack and Eisenack 2018), whereas the case typology approach implies that cases are classified in exactly one archetype. The building blocks and case typology approaches are equivalent only if the dynamics of the considered phenomenon are best explained by exactly one causal mechanism per case (i.e., one building block per case). Otherwise, building blocks decompose cases into particular configurations of attributes of cases that recur across cases.
Archetypes for pattern identification, diagnosis, or scenario development

A second key difference between multiple meanings of archetypes relates to the function that the archetype concept fulfills in a study. Three main functions are prevalent in our systematic review: empirical pattern identification, diagnosis, and scenario development.

First, researchers most frequently use the archetypes approach to identify patterns across large numbers of cases. This use always builds on empirical data. Even though archetypes are identified inductively, theory plays an important role because it informs the selection of indicators for statistical analyses (Cullum et al. 2016, Kok et al. 2016) and the iterative development of the codebook for meta-analyses (Dell'Angelo et al. 2017b).

Second, archetypes are used as diagnostic tools (Braun 2002). In this function, archetypes convey established knowledge about causal effects from prior research. Researchers use them to diagnose their system of concern or to test posited causal effects in new empirical work. For instance, Mokhtar and Aram (2017) used a "limits to growth" system archetype to diagnose dynamics in groundwater management in the Firuzabad Plain, Iran. A different variety of the diagnostic function is found in studies that construct a novel typology deductively without empirical pattern identification. For instance, Fischer et al. (2017) used deductive reasoning to propose four archetypical states of social-ecological systems with different relations between food security and biodiversity conservation. Archetypes are then developed as a new typological theory (George and Bennet 2005).

Third, researchers use archetypes for scenario development, where they serve to distinguish multiple future scenarios of the system of concern, often combined with stakeholder engagement (Hunt et al. 2012, Wardropper et al. 2016). For instance, the Intergovernmental Panel on Biodiversity and Ecosystem Services used scenario archetypes to classify sets of internally consistent scenarios that embody common characteristics (van Vuuren et al. 2012, IPBES 2016).

Overall, the precise meaning of the notion of archetype and the methods employed differ along these three functions. Any single study should characterize its specific use of archetypes with reference to these three functions to enhance the coherence of future research.

\section{Causal analysis and theory development}

Archetype analysis can assume a specific role in scientific efforts for causal analysis and theory development. We understand causality as the explanation of how a cause (e.g., factors, interventions, or events) influence outcomes (Pearl 2009). Causal analysis involves establishing causal effects (producing a causal inference by analyzing how change in a factor $\mathrm{X}$ implies changes in outcome $\mathrm{Y}$ ) and causal mechanisms (explaining the processes through which the effect occurs; Meyfroidt 2016).

Methodologies to advance theories and infer from data to causal statements in sustainability research can be broadly classified into variance-based methods and case-based methods (Magliocca et al. 2015, Beach and Pedersen 2016). Methods for variance-based causal analysis include natural experiments, comparative case studies, multivariate models, matching, instrumental variables, and time-series analysis to provide empirical evidence for or 
against causal hypotheses rooted in theories. Methods for casebased causal analysis include process tracing and congruence methods to provide empirical evidence for or against the causal effects and causal mechanisms of a theory (Beach and Pedersen 2016, Meyfroidt 2016). Although these methods are associated with different epistemological positions, implications for case selection, operationalization of concepts, and inductive or deductive logics, they share the ambition of answering explanatory questions of how and why a phenomenon occurs (George and Bennett 2005). Notably, a theory is not the result of a single study using any one of these methods. Instead, a theory arises in the form of cumulative knowledge from numerous studies that systematically identify, test, and refine posited causal effects and causal mechanisms for a particular domain.

Archetype analysis can assume two roles for linking data to causal statements. First, in analyses of primary data, the archetypes approach is a particular way of practicing the abovementioned methods because it searches for causal statements in a particular way. An archetype lens looks for multiple causal models (rather than seeking to explain the data through one general model), it seeks to identify patterns that recur across cases (rather than a single case study), and it expresses causal statements at an intermediate level of abstraction (rather than an in-depth case description or a reductionist account of single factors).

Second, the construction of archetypes (e.g., in the form of causal graphs) can serve as a boundary object to synthesize findings on causal effects and causal mechanisms that were identified through different methods for numerous cases. One methodology for this construction of archetypes is a "model-centered meta-analysis of case studies" (Rudel 2008, Oberlack et al. 2016). It searches for patterns in the causal statements that primary studies have identified and assesses the contextual conditions for which the causal models are valid (Magliocca et al. 2018).

Notably, not all previous archetype analyses have addressed causality explicitly. Studies that identify archetypes as case typologies often aim at a thick description of their phenomenon of concern, or when they use hypotheses to select variables and indicators, they identify causal factor configurations. Studies that construct archetypes as building blocks tend to identify patterns of causal effects and causal mechanisms.

\section{Archetypes and related approaches}

Archetype analysis builds on or complements several related approaches and tools. These include middle-range theories, ideal types, and box-and-arrow frameworks.

\section{Middle-range theories}

Middle-range theories can be defined as "contextual generalizations that describe chains of causal mechanisms explaining a well-bounded range of phenomena, as well as the conditions which trigger, enable, or prevent these causal chains" (Meyfroidt et al. 2018:53). In contrast with grand theories, they specify a narrower range of conditions under which their posited causal effects are valid, but unlike case-specific explanations, they explain regularities across cases (Merton 1968, Meyfroidt et al. 2018). Archetype analysis provides one methodological approach to developing middle-range theories, if archetypes are used in the sense of building blocks and for pattern identification. The building blocks specify the causal effects that are recurrently observed in empirical case studies. However, a single metaanalysis of case studies is not enough to develop a theory. It may yield a suite of archetypes, but because of the well-known limitations of meta-analyses (e.g., biases, missing data; Delaney et al. 2018, Magliocca et al. 2018), follow-up studies need to test and refine these inductively developed archetypes. In that sense, archetype analyses do not constitute, but can contribute to, the development of middle-range theories.

Ideal types

Ideal types in Max Weber's (1988) sense are mental constructs that simplify the essential aspects of empirical reality into extreme, hypothetical constructs. If archetypes are developed in a purely deductive manner, the resulting archetypes are often synonymous with ideal types. However, there is also the inductive approach in which recurrent patterns are identified within a set of empirical case studies. For example, if black and white are extreme ideal types, archetypes built from an inductive pattern analysis would synthesize the various shades of grey found in empirical case studies. The advantage of using the term "archetypes" rather than "ideal types" lies in the empirical validity and detailed configurations of factors embodied in archetypes, as opposed to the extreme, hypothetical constructs embodied in ideal types.

\section{Box-and-arrow frameworks}

Sustainability researchers commonly organize the main analytical categories of their studies in box-and-arrow frameworks (Lambin and Geist 2008). One example is the social-ecological systems framework of Ostrom (2009). It provides a conceptual map of some 50 variables associated with social-ecological systems sustainability. Box-and-arrow frameworks are suitable tools with which to organize a larger set of variables into a comprehensible conceptual structure (Schlager 2007), communicate complexity to readers (Lambin and Geist 2008), and help diagnose the systems of concern (Ostrom 2009, Partelow 2018). However, they do not specify the precise relations between the variables. Archetype analysis, in the sense of building blocks and pattern identification, uses and extends such frameworks. While box-andarrow frameworks depict a set of variables, archetypes go a step further by providing knowledge about the recurrent configurations and associations among those variables.

\section{MOTIVATIONS FOR ARCHETYPE ANALYSIS IN SUSTAINABILITY RESEARCH}

The results of the survey and systematic review show that archetype analysis is used to address six knowledge problems that persistently challenge sustainability researchers, policy makers, and practitioners (Fig. 2). These six knowledge problems are: idiographic traps and research fragmentation, overgeneralization in global narratives, diagnosis, panacea traps, methodological interplay, and scenario development. We next explain how researchers have used archetype analysis to address each of these six challenges.

\section{Motivation 1: cumulative learning from case studies: tackling idiographic traps and research fragmentation}

The most frequent motivation for analyzing archetypes is cumulative learning across cases and contexts. Interactions in social-ecological systems are complex, multifactorial, and contextual (Folke et al. 2005). Accordingly, researchers often 
apply case study research designs, which enable in-depth understanding of interactions, outcomes, and causal effects at a high level of contextual detail (Beach and Pedersen 2016). However, a recognized limitation of case studies is their restricted validity beyond the immediate study sites (Poteete et al. 2010). This restriction limits the understanding of the conditions for which specific knowledge claims from case studies hold, which results are generalizable, and how contextual factors modify general insights.

Fig. 2. Frequency of the six main motivations for conducting archetype analysis reported, based on a systematic literature review. A study can have one or more motivations.

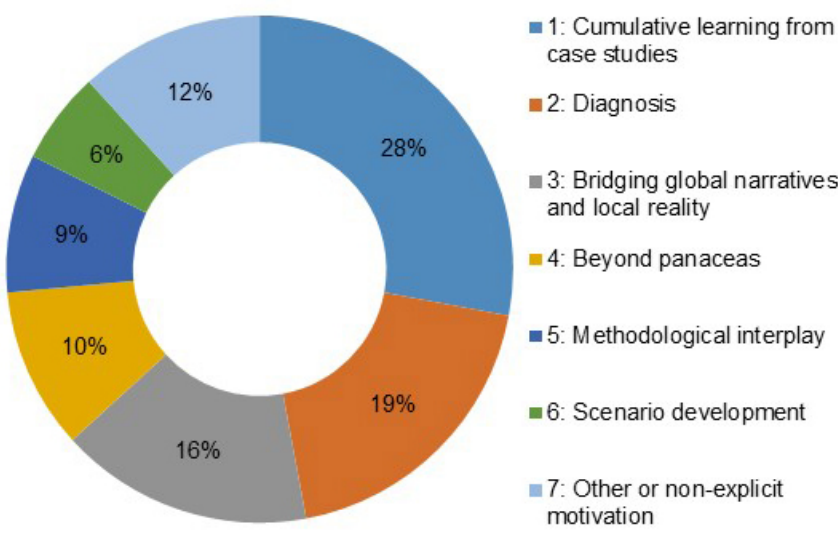

Furthermore, in rapidly expanding research fields, scientific knowledge quickly becomes scattered across hundreds of case studies, making it difficult for individual researchers to follow (Poteete et al. 2010). Without systematic synthesis procedures, learning in science and policy making cannot keep pace with the accumulated evidence and "intellectual gold of case study research" (Jensen and Rodgers 2001:235). Idiographic traps emerge when researchers embrace the complexity of socialecological systems without thoroughly examining similarities and differences with other cases. The significance of "yet another case study" then becomes questionable.

Archetypes offer a methodological approach to foster cumulative learning from case studies in a systematic way. They generalize case study results through multiple explanatory models (Oberlack 2017). Analysts can assess the commonalities and particularities of a single case by relating it to a suite of archetypes (Václavík et al. 2016). Further, inductive pattern analysis scrutinizes how context influences the outcome of interest by analyzing the conditions under which particular archetypes arise (Kummu et al. 2016).

\section{Motivation 2: diagnosis}

Researchers have used archetypes not only as outcomes but also as starting points for new studies. They use knowledge about archetypes from earlier work as a diagnostic tool in new empirical research, where it helps them diagnose the system of concern and avoid problems of omitted variables. For instance, Banson et al. (2016) used established system archetypes, i.e., limits to growth, shifting the burden, success to the successful, escalation, accidental adversaries, and tragedy of the commons, as a diagnostic tool to anticipate potential problems in the agricultural sector of Ghana. They used the causal diagrams of these archetypes to identify leverage points for strategies to enhance sustainability.

The archetypes approach also facilitates the transfer of findings across cases (Eisenack et al. unpublished manuscript, http:// citeseerx.ist.psu.edu/viewdoc/download?doi=10.1.1.572.4210\&rep= rep1\&type=pdf). For example, land system archetypes have recently been applied in a large German research program on sustainable land management. They served to quantify the similarity of land systems across the world in relation to the program's regional projects to identify areas to which regional results could potentially be transferred (Václavík et al. 2016). Similarly, archetypes can help to fill knowledge gaps in countries with limited primary research by extrapolating knowledge from known contexts to similar contexts for which collection of primary data is not possible.

\section{Motivation 3: bridging the gap between global narratives and local realities: tackling problems of overgeneralization}

Local (place based) and global sustainability insights have been developing in parallel, but there is a clear need for their integration (Rindfuss et al. 2004, Balvanera et al. 2017). One barrier to integration is that global narratives, for example, on food security, land grabbing, or climate adaptation, may disregard critical heterogeneity of local realities and therefore provide overgeneralized explanations of the considered phenomenon. The ambition and need in policy and scientific communities to generate global narratives contrasts with the common understanding that every case is unique and that context matters (van Vliet et al. 2016). Archetype analysis bridges the gap between local realities and global narratives by contextualizing their typical elements and generating refined narratives that are explicit about the nuanced contextual conditions while providing generalized findings.

Analyses of global change syndromes (Schellnhuber et al. 1997, Petschel-Held et al. 1999, Hurni et al. 2004, Crona et al. 2015, Dell'Angelo et al. 2018), anthropogenic biomes (anthromes; Ellis and Ramankutty 2008, Martin et al. 2014), vulnerability archetypes (Jäger et al. 2007), global threats to sustainability (Dell'Angelo et al. 2017a), land-use systems (van Asselen and Verburg 2012), or land system archetypes (Václavík et al. 2013) are typical efforts to better understand linkages between global and local sustainability. The term "syndrome" refers to the etymological ancient Greek meaning of "things running together" and to the medical and normative meaning of a complex "clinical" phenomenon with concurring symptoms. The syndrome approach decomposed global change dynamics into 16 functional patterns of environmental degradation and identified the propensity of specific geographies to specific syndromes (Lüdeke et al. 2004, Sietz et al. 2006, Manuel-Navarrete et al. 2007).

Anthromes presented an innovative view of a humantransformed biosphere based on empirical analyses of global land-cover and population data. This global framework has been 
used to map regional differences in the rate of landscape transformation over centuries (Ellis et al. 2010) and to describe the distribution of sustainability strategies and conservation efforts across anthromes (Ellis 2013, Martin et al. 2014).

Archetypes of vulnerability are patterns of human-nature interactions that generate vulnerability. Jäger et al. (2007) show that 10 years of additional research on human-nature interactions has confirmed essential mechanisms such as the poverty-degradation spiral described by the syndromes of global change. Going beyond the syndromes approach, archetypes of vulnerability explicitly capture environmental opportunities such as better water availability and soil fertility in drylands as a basis for designing strategies to reduce risk and enhance food and livelihood security (Jäger et al. 2007, Sietz et al. 2011).

Taken together, these analyses of archetypical patterns provide global assessments of their phenomenon of concern (vulnerability, global change, human-transformed biosphere). They recognize the diversity of local realities by generating global assessments composed of multiple patterns rather than just one and identifying indicators of the conditions under which a pattern may occur in individual cases.

\section{Motivation 4: transferring knowledge about strategies for sustainability across cases: going beyond panaceas}

Although tempting, the search for general principles to guide governance of social-ecological systems has been plagued by the problem that panaceas often fail, disproving the assumption that the performance of governance strategies is independent of the social and ecological context in which they operate (Ostrom et al. 2007). For example, government efforts to rationalize environmental management often contributed to failures because uniform policy prescriptions (panaceas) did not work across the heterogeneous contexts in which they were implemented (Holling and Meffe 1996, Acheson 2006). This implies that general principles for governance and management may apply across a number of contexts but may be useless or even counterproductive in others.

The transfer of knowledge about sustainability strategies is inherently difficult because this knowledge is typically derived from case studies rooted in a particular place and context (van Vliet et al. 2016). Transferring insights into sustainability strategies that proved effective in one place to other places requires identification of recurrent patterns of geographical context and social-ecological problem structure; they must be similar in the source and target cases (Epstein et al. 2015, Kok et al. 2016). Archetypes identify these similarities in biophysical and socioeconomic conditions, processes, problem structures, and governance measures, and can thereby facilitate learning among actors experiencing similar problems. A key assumption is that strategies are indeed transferable among cases that share particular archetypes (Eisenack et al. unpublished manuscript, http://citeseerx.ist.psu.edu/viewdoc/download?doi=10.1.1.572.4210\&rep= rep1\&type $=$ pdf). The knowledge claim that an archetype embodies needs to be tested carefully in the particular contexts in which it is made.

For instance, archetype analyses have shown that general strategies for sustainable agricultural intensification (e.g., halting cropland expansion and closing yield gaps) cannot be applied in a one-size-fits-all manner. Land system archetypes have demonstrated how similarities in land systems across the globe, but also a diversity of land-use patterns at a subnational scale, can help tailor intensification strategies to particular contexts (Václavík et al. 2013). Nested archetypes of vulnerability can inform the regional transfer of archetypical strategies for sustainable intensification, as shown in the drylands of subSaharan Africa (Sietz et al. 2017). Insights into the nestedness of archetypes enabled a more nuanced discussion of vulnerability, food security, and sustainable intensification opportunities. However, any archetypical strategy developed and applied successfully in one location (e.g., planting pits to intensify agricultural production) needs to be adjusted to local conditions elsewhere (e.g., different types of organic material available) if transferred.

\section{Motivation 5: methodological interplay through archetype analysis: working together}

Advances in sustainability research are achieved with different methods, including case studies, statistical analysis, field and laboratory experiments, and modeling (Young et al. 2006, Brown et al. 2013, Magliocca et al. 2015). However, cumulative learning across studies can be limited because these methods cannot be easily integrated in a coherent assessment of the phenomenon of interest (Poteete et al. 2010).

The construction and refinement of archetypes can serve as a boundary object in an "intermethodological" debate. For example, in research on the global land rush, evidence has been generated mainly by means of qualitative local case studies and national to global inventories of large-scale land acquisitions. Limited interplay between these methods and levels constrained their cross-fertilization (Scoones et al. 2013, Magliocca et al. 2019). The analysis of archetypes of large-scale land acquisitions has helped to link the two methodologies by investigating the relevance of factors compiled in inventories by means of metaanalysis of case studies, synthesizing new key factors from case studies to inform inventories, and linking spatial patterns of land acquisitions with implementation processes (Messerli et al. 2014, 2016, Oberlack et al. 2016, Dell'Angelo et al. 2017b, 2018).

Archetypes can also guide collaboration across different levels of abstraction within a research program. For example, governance at the water-energy-food nexus is subject to multiple collective action problems (Pahl-Wostl 2019). A recent analysis of action situation networks elicited configurations of archetypical situations that explain varying performance in irrigation systems in India and Spain (Kimmich and Villamayor-Tomás 2019). This network analysis builds on game-theoretic models and laboratory experiments with archetypical action situations that provide insights on leadership, communication, and institutional change (Ostrom 2005, Poteete et al. 2010). Further, contextualized field experiments specified the domain of validity of laboratory experiments (Müller et al. 2018), and an analytic narrative method helped to explain under which conditions the network equilibria change (Kimmich 2016).

In sum, archetype analysis can foster dialogue and crossfertilization between different methods, disciplines, epistemologies, and theories. This is the case when archetypes serve as boundary objects that researchers jointly construct, test, criticize, and refine over time. 


\section{Motivation 6: scenario development}

Well-established knowledge about archetypes is sometimes used prospectively for scenario development. For instance, Turner et al. (2017) used the causal diagrams of the "success-to-thesuccessful" and "fixes-that-backfire" system archetypes introduced by Senge (1990) to inform the development and assessment of policy scenarios in dealing with agricultural land transformation in the north central United States. Another strand of research has developed the notion of "scenario archetypes." These are families of scenarios that share a set of assumptions (Gallopín et al. 1997, Hunt et al. 2012, van Vuuren et al. 2012). For instance, Kubiszewski et al. (2016) used the four Great Transition Initiative archetypes to assess the value of ecosystem services in Asia and the Pacific. Pereira et al. (2018) used transformative visioning to develop archetypal scenarios of the Anthropocene in southern Africa.

\section{POTENTIAL AND LIMITATIONS OF ARCHETYPE ANALYSIS IN SUPPORTING EVIDENCE-BASED, CONTEXT-SENSITIVE LAW AND POLICY MAKING}

Analyzing sustainability strategies using the archetypes approach The results of the systematic review show how scholars have analyzed sustainable development strategies using the archetypes approach (Fig. 3). The first and largest set of studies develops "system archetypes" or "problem archetypes" for specific sustainability domains. These archetypes explain common patterns in the systems of concern. As diagnostic tools, they provide insight into the factors and processes that generate outcomes; as prospective tools, they predict potential trajectories. This systems knowledge is then used to inform the discussion of policy or management interventions by analyzing how particular interventions may modify system behavior leading to sustainability-related outcomes (Banson et al. 2016). Furthermore, these studies facilitate the transfer of knowledge about sustainability strategies across similar cases that share the same archetype. For instance, Sietz et al. (2017) use spatially explicit archetypes of vulnerability in African drylands to identify areas with good prospects for sustainable intensification.

Fig. 3. Three main options for analyzing sustainability strategies using the archetypes approach, based on a systematic literature review.

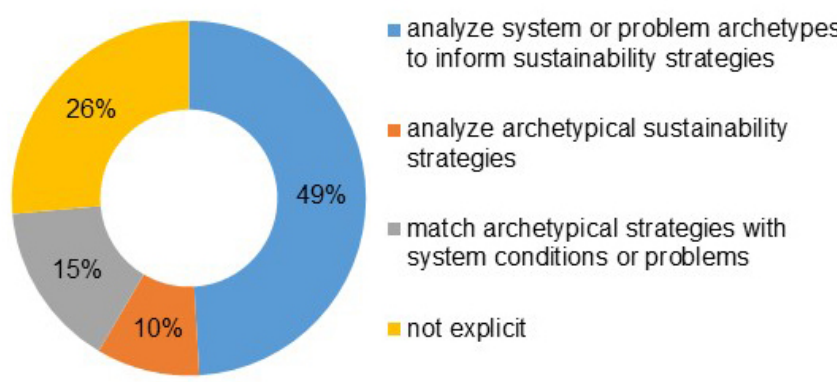

The second set of studies analyzes "solution archetypes," "policy archetypes," or "strategy archetypes," which are archetypical options in dealing with a specific situation (Wolstenholme 2003).
For example, Bocken et al. (2014) present archetypical business models associated with innovations for sustainability. Luederitz et al. (2017) synthesize archetypical pathways to sustainability.

The third set of studies combines the characteristics of the first two by empirically assessing which policy or strategy archetypes are suited to which contexts, systems, or problem archetypes. For example, Jäger et al. (2015) assess the robustness of four archetypical climate adaptation measures across sectors and scenarios. Brzezina et al. (2017:1) use archetypes to "anticipate difficulties in the development of organic farming in the [European Union]" and to "find ways to address these difficulties."

The literature shows various examples of how archetype analysis has been integrated into transdisciplinary research (Hurni et al. 2004, Brezenina et al. 2017), assessment processes (Jäger et al. 2007), or scenario development (Wardropper et al. 2016) in which the joint involvement of researchers, decision makers, and stakeholders contributed to the analysis. Archetypes served as a boundary concept in the joint participatory analysis of problems and solutions.

\section{Potential contributions of archetype analysis to evidence-based, context-sensitive law and policy making}

Sustainability research is strongly linked to societal learning and decision-making processes at all scales from local to global (Miller et al. 2014). Such processes involve diverse knowledge needs, which partly depend on the scales of decision making (Rist et al. 2006). For instance, decision making at the village level requires highly context-specific knowledge to tailor rules to the context, whereas policy making at the United Nations level requires generalized knowledge to craft rules that apply meaningfully across multiple contexts (Oberlack and Eisenack 2014). Archetype analysis can be one component in the methodological portfolio of sustainability research (Young et al. 2006) to meet such knowledge demands at multiple scales. The context-sensitive generalizations embodied in archetypes can be useful in multiple ways.

First, law and policy making in larger jurisdictions that cover many cases of a given phenomenon is in need of generalized but context-sensitive knowledge to ensure that laws and policies are tailored to the different contexts. However, governance at higher levels is frequently confronted with patchy evidence from scattered localized research. Archetype analysis constitutes a methodological approach to inform policy making at higher jurisdictional levels through context-sensitive generalizations with case-level empirical validity (Newell et al. 2011). For instance, governments, policy experts, scientists, and other stakeholders framed archetypes of vulnerability at a global scale in a participatory process providing a bridge between science and decision making for vulnerability reduction (Jäger et al. 2007). The "archetypes of livelihood vulnerability and sustainability" (Oberlack et al. 2016) provided a starting point for transdisciplinary discussions about Swiss stakeholders' strategies in dealing with large-scale land acquisitions in the Global South.

Second, the scales of both decision making and knowledge are historically and institutionally produced. The former are the result of administrative divisions created to govern territories and processes from local to global levels, whereas the latter result from 
academic processes through which phenomena are identified, framed, and reframed into scientific disciplines. These two processes of scale production are not necessarily aligned. In the Anthropocene, the rates of both newly identified and anthropogenically created phenomena are accelerating (Ellis 2018). This situation increases the potential for misalignments, which can lead to disastrous decisions that do not take into account consequences and shocks anticipated by existing knowledge. Archetype analysis can contribute to realigning decision-making and knowledge scales by generating interdisciplinary knowledge about multiscale phenomena in which local patterns are causally connected to national and global processes (Adger et al. 2003). To ensure that the scales of knowledge production match the relevant scales of decision making, any archetype analysis requires prior reflection on choices of social-ecological system boundaries, scales of agency, observables, and data availability.

Third, rules and regulations always seek to structure societal processes in a generalized way (Ostrom 2005). The tension between crafting rules and doing justice to the diversity of individual cases has always been inherent in law and policy making (Barnes 2013). Accordingly, legal techniques exist that allow for context-sensitive solutions within general rules. For instance, there is a "no good rule without an exemption clause," with exemptions being activated under certain conditions. The principle of subsidiarity holds that rules at higher levels of governance take a more general form to leave room for contextsensitive concretization at lower levels. Similarly, some legal frameworks are confined to stipulate only core benchmarks but prescribe that well-structured procedures need to be undergone at a lower level of governance before decisions are taken. Finally, human rights law, while establishing the fundamental principles of equality and nondiscrimination, asks for differentiation and for treating "similar situations equally and different situations differently" (Baetens 2010). By contrast, trade law refers to a stricter principle of nondiscrimination; it concedes "special and differential treatment" to economically more vulnerable countries only temporarily and to a very limited extent. Sustainability theorists have suggested adapting trade law toward a broader approach to differentiation, as it is practiced in human rights law, allowing for differential treatment ab initio following graduation tools based on economic, social, and environmental records, and hence, for fairer solutions based on empirical knowledge (Bürgi Bonanomi 2015).

Archetype analyses can assist policy makers and legal practitioners in applying such techniques while seeking to navigate the tension between generalization and context sensitivity. Archetypes help determine whether certain situations should be regarded as equal and requiring equal treatment or whether unequal treatment is more justified. Although it is arbitrary to derive general arguments from individual case studies, knowledge about recurrent patterns makes empirical learning more accessible for decision making in larger jurisdictions.

One example is the regulation of palm oil markets in trade agreements. The European Free Trade Agreement countries were negotiating trade agreements with Malaysia and Indonesia in 2018. Although Indonesia and Malaysia are requesting improved market access, stakeholders in the European Free Trade Agreement countries are criticizing sustainability issues in palm oil production. As a compromise, the idea of preferential quota for sustainably produced palm oil has gained momentum. However, the meaning of sustainability in this context remains contentious. Case studies have illustrated diverse nuances of palm oil production in both countries, but common denominators remain difficult to observe. An archetype analysis might help to determine whether the sustainability challenges differ between types of production, regions, or countries, and what elements are similar. Depending on these results, preferential market access could be conditioned on, for example, procedural prerequisites requiring stakeholders to define the context-specific criteria of sustainable production in a novel way. Alternatively, the analysis may result in the conclusion that adherence to existing labels is appropriate.

\section{Current limitations of archetype analysis}

The archetypes approach faces a number of limitations. First, archetype analysis is based on the assumption that insights from one case can be transferred to another case if the same archetypes apply to both cases. This assumption needs to be tested systematically and empirically. To what extent can system or problem archetypes actually explain the effectiveness of policy or strategy archetypes? If the same policy or strategy shows different effects in cases characterized by the same system or problem archetypes, the latter need to be refined, for example by nesting archetypes (Sietz et al. 2017) and by identifying more precise conditions to which particular archetypes apply (Magliocca et al. 2018).

Second, any particular method for analyzing archetypes, such as meta-analysis, cluster analysis, or system modeling, has its own specific challenges (Sietz, Frey, Roggero, et al. unpublished manuscript). We refer to method-specific literature on how to deal with those challenges. For quality criteria that hold across methods, we refer to Eisenack et al. (2019).

Third, the quality, availability, and comparability of data are persistent challenges in conducting research based on large samples of case studies (Margulies et al. 2016, Magliocca et al. 2018). Coordinated research networks, common analytical frameworks, standardized research instruments, and online databases of case studies (e.g., EJAtlas, LandMatrix, SES Library, SESMAD) have alleviated some of the data quality and availability challenges (Poteete and Ostrom 2008), but longitudinal data availability for causal analysis remains severely limited.

Fourth, the treatment of causality is notoriously difficult in comparative analyses (Meyfroidt 2016). Studies frequently analyze causal factors that influence the outcomes of interest (e.g., Geist and Lambin 2002, Frey 2017), whereas synthesis of causal mechanisms is more limited to date.

\section{CONCLUSION}

Here, we offer a comprehensive overview of the meanings of archetype analysis in sustainability research, the motivations behind it, and its policy relevance. A common understanding of archetypes is emerging: they are context-sensitive, generalized models of sustainability problems, dynamics, or strategies with case-level empirical validity. Archetypes are empirically testable, mental representations that are always defined in relation to a specific research question, purpose, or knowledge need. Archetype analysis investigates recurrent patterns of the phenomenon of interest at an intermediate level of abstraction to identify multiple 
models that explain the phenomenon under particular conditions.

Archetype analysis is best conceived as a methodological approach, rather than a particular method, framework, or theory. It seeks to strike a balance between retaining the richness of case studies while identifying generalizable patterns, which makes it particularly suited for research settings characterized by heterogeneous cases. As an epistemologically, theoretically, and thematically open approach, archetypes can function as boundary objects in inter- and transdisciplinary research.

We suggest the following priorities for future research on archetypes. First, once they are identified, archetypes provide a starting point for new empirical research to test, revise, or refine particular archetypes and the hypotheses they embody. Second, only a few explicitly dynamic archetype analyses have been undertaken so far (e.g., Lüdeke et al. 2014, Levers et al. 2018, Magliocca et al. 2019); future archetype analyses need to capture change in the systems of concern. Third, a suite of archetypes needs to be tested not only for its ability to explain the phenomenon of interest, but also for its power to transfer knowledge about effective sustainable development strategies across cases. Finally, enhanced application of archetypes in science-society-policy settings to support the design and evaluation of policies and strategies is an area of future activities that may be highly relevant to supporting sustainable development at local to global scales.

Responses to this article can be read online at: http://www.ecologyandsociety.org/issues/responses. php/10747

\begin{abstract}
Acknowledgments:
We gratefully acknowledge comments by Volker Beckmann and participants of the "Second Research Workshop on Archetype Analysis in Sustainability Research" (HU Berlin, 28 February-2 March 2018), which improved an earlier draft of the paper. Marlène Thibault provided valuable language editing. This work has received financial support from the Swiss National Science Foundation (grant IZ32Z0_173396); the European Research Council under the European Union's Horizon 2020 research and innovation program (grant agreement 677140 MIDLAND; https://ercmidland.earth); the Institute of Geography, University of Bern (research cluster "Governing telecoupled resource systems for environmental justice"); the Centre of Development and Environment, University of Bern; the Mittelbauvereinigung, University of Bern; Humboldt-Univeristät zu Berlin (Resource Economics Group ); and the NASA ROSES Land Cover Land Use Change project LCLUC project (award NNX17AI15G). This study contributes to the Global Land Programme (https://glp. earth).
\end{abstract}

\section{LITERATURE CITED}

Acheson, J. M. 2006. Institutional failure in resource management. Annual Review of Anthropology 35:117-134. https:// doi.org/10.1146/annurev.anthro.35.081705.123238
Adger, W. N., K. Brown, J. Fairbrass, A. Jordan, J. Paavola, S. Rosendo, and G. Seyfang. 2003. Governance for sustainability: towards a 'thick' analysis of environmental decisionmaking. Environment and Planning A 35(6):1095-1110. https://doi. org/10.1068/a35289

Baetens, F. 2010. The concept of equality in international trade and investment law: a catalyst for sustainable development. Pages 251-272 in D. French, editor. Global justice and sustainable development. Nijhoff, Leiden, The Netherlands.

Balvanera, P., R. Calderón-Contreras, A. J. Castro, M. R. FelipeLucia, I. R. Geijzendorffer, S. Jacobs, B. Martín-López, U. Arbieu, C. Ifejika Speranza, B. Locatelli, N. Pérez Harduindeguy, I. Ruiz Mercado, M. J. Spierenburg, A. Vallet, L. Lynes, and L. Gillson. 2017. Interconnected place-based social-ecological research can inform global sustainability. Current Opinion in Environmental Sustainability 29:1-7. https://doi.org/10.1016/j. cosust.2017.09.005

Banson, K. E., N. C. Nguyen, and O. J. H. Bosch. 2016. Using system archetypes to identify drivers and barriers for sustainable agriculture in Africa: a case study in Ghana. Systems Research and Behavioral Science 33(1):79-99. https://doi.org/10.1002/ sres. 2300

Barnes, R. A. 2013. The capacity of property rights to accommodate social-ecological resilience. Ecology and Society 18 (1):6. http://dx.doi.org/10.5751/ES-05292-180106

Beach, D., and R. B. Pedersen. 2016. Causal case study methods. foundations and guidelines for comparing, matching, and tracing. University of Michigan Press, Ann Arbor, Michigan, USA. https://doi.org/10.3998/mpub.6576809

Bennett, E. M., G. S. Cumming, and G. D. Peterson. 2005. A systems model approach to determining resilience surrogates for case studies. Ecosystems 8(8):945-957. https://doi.org/10.1007/ s10021-005-0141-3

Bocken, N. M. P., S. W. Short, P. Rana, and S. Evans. 2014. A literature and practice review to develop sustainable business model archetypes. Journal of Cleaner Production 65:42-56. https:// doi.org/10.1016/i.jclepro.2013.11.039

Braun, W. 2002. The system archetypes. Self-published manuscript. [online] URL: https://www.albany.edu/faculty/gpr/ PAD724/724WebArticles/sys archetypes.pdf

Brown, D. G., P. H. Verburg, R. G. Pontius Jr., and M. D. Lange. 2013. Opportunities to improve impact, integration, and evaluation of land change models. Current Opinion in Environmental Sustainability 5(5):452-457. https://doi.org/10.1016/ j.cosust.2013.07.012

Brzezina, N., K. Biely, A. Helfgott, B. Kopainsky, J. Vervoort, and E. Mathijs. 2017. Development of organic farming in Europe at the crossroads: looking for the way forward through system archetypes lenses. Sustainability 9(5):821. https://doi.org/10.3390/ $\underline{\text { su9050821 }}$

Bürgi Bonanomi, E. 2015. Sustainable investment in land in the Global South: What would it require from a coherence perspective? The case of Sierra Leone. Questions of International Law 21:17-37. [online] URL: http://www.qil-qdi.org/sustainable- 
investment-in-land-in-the-global-south-what-would-it-require-froma-coherence-perspective-the-case-of-sierra-leone/

Cox, M. 2008. Balancing accuracy and meaning in common-pool resource theory. Ecology and Society 13(2):44. https://doi. org/10.5751/ES-02683-130244

Cox, M. 2014. Understanding large social-ecological systems: introducing the SESMAD project. International Journal of the Commons 8(2):265-276. https://doi.org/10.18352/ijc.406

Crona, B. I., T. van Holt, M. Petersson, T. M. Daw, and E. Buchary. 2015. Using social-ecological syndromes to understand impacts of international seafood trade on small-scale fisheries. Global Environmental Change 35:162-175. https://doi.org/10.1016/ j.gloenvcha.2015.07.006

Cullum, C., K. H. Rogers, G. Brierley, and E. T. F. Witkowski. 2016. Ecological classification and mapping for landscape management and science: Foundations for the description of patterns and processes. Progress in Physical Geography 40 (1):38-65. https://doi.org/10.1177/0309133315611573

Delaney, A., T. Evans, J. McGreevy, J. Blekking, T. Schlachter, K. Korhonen-Kurki, P. A. Tamás, T. A. Crane, H. Eakin, W. Förch, L. Jones, D. R. Nelson, C. Oberlack, M. Purdon, and S. Rist. 2018. Governance of food systems across scales in times of socialecological change: a review of indicators. Food Security 10 (2):287-310. https://doi.org/10.1007/s12571-018-0770-y

Dell'Angelo, J., P. D'Odorico, and M. C. Rulli. 2017a. Threats to sustainable development posed by land and water grabbing. Current Opinion in Environmental Sustainability 26-27:120-128. https://doi.org/10.1016/j.cosust.2017.07.007

Dell'Angelo, J., P. D’Odorico, and M. C. Rulli. 2018. The global water grabbing syndrome. Ecological Economics 143:276-285. https://doi.org/10.1016/j.ecolecon.2017.06.033

Dell'Angelo, J., P. D’Odorico, M. C. Rulli, and P. Marchand. 2017b. The tragedy of the grabbed commons: coercion and dispossession in the global land rush. World Development 92:1-12. https://doi.org/10.1016/j.worlddev.2016.11.005

Eisenack, K. 2012. Archetypes of adaptation to climate change. Pages 107-122 in M. Glaser, G. Krause, B. M. W. Ratter, and M. Welp, editors. Human-nature interactions in the Anthropocene: potentials of social-ecological systems analysis. Routledge, New York, New York, USA.

Eisenack, K., A. Gotgelf, U. Kasymov, M. Lutz, P. Perez, C. Oberlack, and D. Sietz. 2018. Second research workshop archetype analysis in sustainability research. Workshop report, 28th February-2nd March 2018, Humboldt Universität zu Berlin, Germany. [online] URL: https://boris.unibe.ch/121975/1/

Oberlack 2018 Workshop $\% 202$.pdf

Eisenack, K., S. Villamayor-Tomás, G. Epstein, C. Kimmich, N. Magliocca, D. Manuel-Navarrete, C. Oberlack, M. Roggero, and D. Sietz. 2019. Design and quality criteria for archetype analysis. Ecology and Society, in press.

Ellis, E. C. 2013. Sustaining biodiversity and people in the world's anthropogenic biomes. Current Opinion in Environmental Sustainability 5(3-4):368-372. https://doi.org/10.1016/j.cosust.2013.07.002
Ellis, E. C. 2018. Anthropocene: a very short introduction. Oxford University Press, Oxford, UK. https://doi.org/10.1093/ actrade/9780198792987.001.0001

Ellis, E. C., K. K. Goldewijk, S. Siebert, D. Lightman, and N. Ramankutty. 2010. Anthropogenic transformation of the biomes, 1700 to 2000. Global Ecology and Biogeography 19(5):589-606. https://doi.org/10.1111/j.1466-8238.2010.00540.x

Ellis, E. C., and N. Ramankutty. 2008. Putting people in the map: anthropogenic biomes of the world. Frontiers in Ecology and the Environment 6(8):439-447. https://doi.org/10.1890/070062

Epstein, G., J. Pittman, S. M. Alexander, S. Berdej, T. Dyck, U. Kreitmair, K. J. Rathwell, S. Villamayor-Tomás, J. Vogt, and D. Armitage. 2015. Institutional fit and the sustainability of socialecological systems. Current Opinion in Environmental Sustainability 14:34-40. https://doi.org/10.1016/j.cosust.2015.03.005

Fischer, J., D. J. Abson, A. Bergsten, N. F. Collier, I. Dorresteijn, J. Hanspach, K. Hylander, J. Schultner, and F. Senbeta. 2017. Reframing the food-biodiversity challenge. Trends in Ecology and Evolution 32(5):335-345. https://doi.org/10.1016/j.tree.2017.02.009

Folke, C., T. Hahn, P. Olsson, and J. Norberg. 2005. Adaptive governance of social-ecological systems. Annual Review of Environment and Resources 30:441-473. https://doi.org/10.1146/ annurev.energy.30.050504.144511

Frey, U. J. 2017. A synthesis of key factors for sustainability in social-ecological systems. Sustainability Science 12(4):507-519. https://doi.org/10.1007/s11625-016-0395-Z

Frey, U. J., and M. Cox. 2015. Building a diagnostic ontology of social-ecological systems. International Journal of the Commons 9(2):595-618. https://doi.org/10.18352/ijc.505

Gallopín, G., A. Hammond, P. Raskin, and R. Swart. 1997. Branch points: global scenarios and human choice. Stockholm Environment Institute, Stockholm, Sweden. [online] URL: https://www.sei.org/publications/branch-points-global-scenarioshuman-choice-resource-paper-global-scenario-group/

Geist, H. J., and E. F. Lambin. 2002. Proximate causes and underlying driving forces of tropical deforestation: tropical forests are disappearing as the result of many pressures, both local and regional, acting in various combinations in different geographical locations. Bioscience 52(2):143-150.

George, A. L., and A. Bennett. 2005. Case studies and theory development in the social sciences. MIT Press, Cambridge, Massachusetts, USA.

Holling, C. S., and G. K. Meffe. 1996. Command and control and the pathology of natural resource management. Conservation Biology 10(2):328-337. https://doi.org/10.1046/j.1523-1739.1996.10020328. $\underline{\mathrm{X}}$

Hunt, D. V. L., D. R. Lombardi, S. Atkinson, A. R. G. Barber, M. Barnes, C. T. Boyko, J. Brown, J. Bryson, D. Butler, S. Caputo, M. Caserio, R. Coles, R. F. D. Cooper, R. Farmani, M. Gaterell, J. Hale, C. Hales, C. N. Hewitt, L. Jankovic, I. Jefferson, J. Leach, A. R. MacKenzie, F. A. Memon, J. P. Sadler, C. Weingaertner, J. D. Whyatt, and C. D. F. Rogers. 2012. Scenario archetypes: converging rather than diverging themes. Sustainability 4 (4):740-772. https://doi.org/10.3390/su4040740 
Hurni, H., U. Wiesmann, and R. Schertenleib, editors. 2004. Research for mitigating syndromes of global change: a transdisciplinary appraisal of selected regions of the world to prepare development-oriented research partnerships. Geographica Bernensia, Bern, Switzerland. [online] URL: http://www.nccrnorth-south.unibe.ch/Pages/Research-for-Mitigating-Syndromesof-Global-Change.aspx

Intergovernmental Science-Policy Platform on Biodiversity and Ecosystem Services (IPBES). 2016. The methodological assessment report on scenarios and models of biodiversity and ecosystem services. IPBES Secretariat, Bonn, Germany. [online] URL: https://www.ipbes.net/sites/default/files/downloads/pdf/2016. methodological assessment report scenarios models.pdf

Jäger, J., M. T. J. Kok, J. C. Mohamed-Katerere, S. I. Karlsson, M. K. B. Lüdeke, G. D. Dabelko, F. Thomalla, I. de Soysa, M. Chenje, R. Filcak, L. Koshy, M. Long Martello, V. Mathur, A. R. Moreno, V. Narain, and D. Sietz. 2007. Vulnerability of people and the environment: challenges and opportunities. Pages 301-360 in Global environmental outlook, GEO-4: environment for development. United Nations Environment Programme. Progress Press, Valletta, Malta. [online] URL: http://wedocs.unep.org/ handle/20.500.11822/19936

Jäger, J., M. D. A. Rounsevell, P. A. Harrison, I. Omann, R. Dunford, M. Kammerlander, and G. Pataki. 2015. Assessing policy robustness of climate change adaptation measures across sectors and scenarios. Climatic Change 128(3-4):395-407. https:// doi.org/10.1007/s10584-014-1240-y

Jensen, J. L., and R. Rodgers. 2001. Cumulating the intellectual gold of case study research. Public Administration Review 61 (2):235-246. https://doi.org/10.1111/0033-3352.00025

Jung, C. G., 1959. The archetypes and the collective unconscious. Routledge, London, UK.

Kimmich, C. 2016. Can analytic narrative inform policy change? The political economy of the Indian electricity-irrigation nexus. Journal of Development Studies 52(2):269-285. https://doi. org/10.1080/00220388.2015.1093119

Kimmich, C., and S. Villamayor-Tomás. 2019. Assessing action situation networks: a configurational perspective on water and energy governance in irrigation systems. Water Economics and Policy 5(1):1850005. https://doi.org/10.1142/S2382624X18500054

Kok, M., M. Lüdeke, P. Lucas, T. Sterzel, C. Walther, P. Janssen, D. Sietz, and I. de Soysa. 2016. A new method for analysing socioecological patterns of vulnerability. Regional Environmental Change 16(1):229-243. https://doi.org/10.1007/s10113-014-0746-1

Kubiszewski, I., S. J. Anderson, R. Costanza, and P. C. Sutton. 2016. The future of ecosystem services in Asia and the Pacific. Asia and the Pacific Policy Studies 3(3):389-404. https://doi. org/10.1002/app5.147

Kugler, P. 1982. The alchemy of discourse: an archetypal approach to language. Bucknell University Press, Lewisburg, Pennsylvania, USA.

Kummu, M., J. H. A. Guillaume, H. de Moel, S. Eisner, M. Flörke, M. Porkka, S. Siebert, T. I. E. Veldkamp, and P. J. Ward. 2016.
The world's road to water scarcity: shortage and stress in the 20th century and pathways towards sustainability. Scientific Reports 6:38495. https://doi.org/10.1038/srep38495

Lambin, E. F., and H. J. Geist, editors. 2008. Land-use and landcover change: local processes and global impacts. Springer, Berlin, Germany.

Lane, D. C. 2008. The emergence and use of diagramming in system dynamics: a critical account. Systems Research and Behavioral Science 25(1):3-23. https://doi.org/10.1002/sres.826

Levers, C., D. Müller, K. Erb, H. Haberl, M. R. Jepsen, M. J. Metzger, P. Meyfroidt, T. Plieninger, C. Plutzar, J. Stürck, P. H. Verburg, P. J. Verkerk, and T. Kuemmerle. 2018. Archetypical patterns and trajectories of land systems in Europe. Regional Environmental Change 18(3):715-732. https://doi.org/10.1007/ $\underline{\text { s10113-015-0907-X }}$

Locke, J. 1690. An essay concerning human understanding. Basset, London, UK.

Lüdeke, M. K. B., G. Petschel-Held, and H.-J. Schellnhuber. 2004. Syndromes of global change: the first panoramic view. Gaia 13 (1):42-49. https://doi.org/10.14512/gaia.13.1.10

Luederitz, C., D. J. Abson, R. Audet, and D. J. Lang. 2017. Many pathways toward sustainability: not conflict but co-learning between transition narratives. Sustainability Science 12 (3):393-407. https://doi.org/10.1007/s11625-016-0414-0

Magliocca, N. R., E. C. Ellis, G. R. H. Allington, A. de Bremond, J. Dell'Angelo, O. Mertz, P. Messerli, P. Meyfroidt, R. Seppelt, and P. H. Verburg. 2018. Closing global knowledge gaps: producing generalized knowledge from case studies of socialecological systems. Global Environmental Change 50:1-14. https:// doi.org/10.1016/j.gloenvcha.2018.03.003

Magliocca, N. R., T. K. Rudel, P. H. Verburg, W. J. McConnell, O. Mertz, K. Gerstner, A. Heinimann, and E. C. Ellis. 2015. Synthesis in land change science: methodological patterns, challenges, and guidelines. Regional Environmental Change 15 (2):211-226. https://doi.org/10.1007/s10113-014-0626-8

Magliocca, N. R., Q. Van Khuc, E. A. Ellicott, and A. de Bremond. 2019. Archetypical pathways of direct and indirect land-use change caused by Cambodia's economic land concessions. Ecology and Society 24(2):25. https://doi. org/10.5751/ES-10954-240225

Manuel-Navarrete, D., J. J. Gómez, and G. Gallopín. 2007. Syndromes of sustainability of development for assessing the vulnerability of coupled human-environmental systems. The case of hydrometeorological disasters in Central America and the Caribbean. Global Environmental Change 17(2):207-217. https:// doi.org/10.1016/j.gloenvcha.2006.07.002

Margulies, J. D., N. R. Magliocca, M. D. Schmill, and E. C. Ellis. 2016. Ambiguous geographies: connecting case study knowledge with global change science. Annals of the American Association of Geographers 106(3):572-596. https://doi.org/10.1080/2469445$\underline{2.2016 .1142857}$

Martin, L. J., J. E. Quinn, E. C. Ellis, M. R. Shaw, M. A. Dorning, L. M. Hallett, N. E. Heller, R. J. Hobbs, C. E. Kraft, E. Law, N. 
L. Michel, M. P. Perring, P. D. Shirey, and R. Wiederholt. 2014. Conservation opportunities across the world's anthromes. Diversity and Distributions 20(7):745-755. https://doi.org/10.1111/ ddi. 12220

Merton, R. K. 1968. Social theory and social structure. Free Press, New York, New York, USA.

Messerli, P., M. Giger, M. B. Dwyer, T. Breu, and S. Eckert. 2014. The geography of large-scale land acquisitions: analysing socioecological patterns of target contexts in the global South. Applied Geography 53:449-459. https://doi.org/10.1016/j.apgeog.2014.07.005

Messerli, P., A. Peeters, O. Schoenweger, V. Nanhthavong, and A. Heinimann. 2016. Marginal land or marginal people? Analysing patterns and processes of large-scale land acquisitions in SouthEast Asia. Pages 136-171 in C. Gironde, C. Golay, and P. Messerli, editors. Large-scale land acquisitions: focus on South-East Asia. Brill, Leiden, The Netherlands. [online] URL: https://www.jstor. org/stable/10.1163/j.ctt1w76v19

Meyfroidt, P. 2016. Approaches and terminology for causal analysis in land systems science. Journal of Land Use Science 11 (5):501-522. https://doi.org/10.1080/1747423X.2015.1117530

Meyfroidt, P., R. R. Chowdhury, A. de Bremond, E. C. Ellis, K.H. Erb, T. Filatova, R. D. Garrett, J. M. Grove, A. Heinimann, T. Kuemmerle, C. A. Kull, E. F. Lambin, Y. Landon, Y. le Polain de Waroux, P. Messerli, D. Müller, J. Ø. Nielsen, G. D. Peterson, V. Rodriguez García, M. Schlüter, B. L. Turner II, and P. H. Verburg. 2018. Middle-range theories of land system change. Global Environmental Change 53:52-67. https://doi.org/10.1016/j. gloenvcha.2018.08.006

Miller, T. R., A. Wiek, D. Sarewitz, J. Robinson, L. Olsson, D. Kriebel, and D. Loorbach. 2014. The future of sustainability science: a solutions-oriented research agenda. Sustainability Science 9(2):239-246. https://doi.org/10.1007/s11625-013-0224-6

Mirchi, A., K. Madani, D. Watkins Jr., and S. Ahmad. 2012. Synthesis of system dynamics tools for holistic conceptualization of water resources problems. Water Resources Management 26 (9):2421-2442. https://doi.org/10.1007/s11269-012-0024-2

Mokhtar, A., and S. Aram. 2017. Systemic insights into agricultural groundwater management: case of Firuzabad Plain, Iran. Water Policy 19(5):867-885. https://doi.org/10.2166/ wp.2017.159

Müller, M., J. Rommel, and C. Kimmich. 2018. Farmers' adoption of irrigation technologies: experimental evidence from a coordination game with positive network externalities in India. German Economic Review 19(2):119-139. https://doi.org/10.1111/ geer. 12117

Newell, B., D. M. Marsh, and D. Sharma. 2011. Enhancing the resilience of the Australian national electricity market: taking a systems approach in policy development. Ecology and Society 16 (2):15. https://doi.org/10.5751/ES-04132-160215

Oberlack, C. 2017. Diagnosing institutional barriers and opportunities for adaptation to climate change. Mitigation and Adaptation Strategies for Global Change 22(5):805-838. https:// doi.org/10.1007/s11027-015-9699-Z
Oberlack, C., and K. Eisenack. 2014. Alleviating barriers to urban climate change adaptation through international cooperation. Global Environmental Change 24:349-362. https://doi.org/10.1016/ j.gloenvcha.2013.08.016

Oberlack, C., and K. Eisenack. 2018. Archetypical barriers to adapting water governance in river basins to climate change. Journal of Institutional Economics 14(3):527-555. https://doi. org/10.1017/S1744137417000509

Oberlack, C., L. Tejada, P. Messerli, S. Rist, and M. Giger. 2016. Sustainable livelihoods in the global land rush? Archetypes of livelihood vulnerability and sustainability potentials. Global Environmental Change 41:153-171. https://doi.org/10.1016/j. gloenvcha.2016.10.001

Oberlack, C., A. Winiger, P. Kupferschmied, D. Sietz, and K. Eisenack. 2017. Research workshop: "analysing archetypes in sustainability research" 2nd-4th May 2017, University of Bern, Switzerland. Workshop report. Wageningen University, Wageningen, The Netherlands. [online] URL: https://boris.unibe. ch/121976/1/Oberlack 2017 Workshop-report.pdf

Ostrom, E. 2005. Understanding institutional diversity. Princeton University Press, Princeton, New Jersey, USA. https://doi. org/10.2307/j.ctt7s7wm

Ostrom, E. 2007. A diagnostic approach for going beyond panaceas. Proceedings of the National Academy of Sciences 104 (39):15181-15187. https://doi.org/10.1073/pnas.0702288104

Ostrom, E. 2009. A general framework for analyzing sustainability of social-ecological systems. Science 325:419-422. https://doi.org/10.1126/science.1172133

Ostrom, E., M. A. Janssen, and J. M. Anderies. 2007. Going beyond panaceas. Proceedings of the National Academy of Sciences 104(39):15176-15178. https://doi.org/10.1073/pnas.0701886104

Pahl-Wostl, C. 2019. Governance of the water-energy-food security nexus: a multi-level coordination challenge. Environmental Science and Policy 92:356-367. https://doi.org/10.1016/j. envsci.2017.07.017

Partelow, S. 2018. A review of the social-ecological systems framework: applications, methods, modifications, and challenges. Ecology and Society 23(4):36. https://doi.org/10.5751/ES-10594-230436

Pearl, J. 2009. Causality: models, reasoning, and inference. Cambridge University Press, Cambridge, UK. https://doi. org/10.1017/CBO9780511803161

Pereira, L. M., T. Hichert, M. Hamann, R. Preiser, and R. Biggs. 2018. Using futures methods to create transformative spaces: visions of a good Anthropocene in southern Africa. Ecology and Society 23(1):19. https://doi.org/10.5751/ES-09907-230119

Petschel-Held, G. 2003. Nomothese und Idiographie in den Nachhaltigkeitswissenschaften. Pages 277-297 in N. GottschalkMazouz and N. Mazouz, editors. Nachhaltigkeit und globaler Wandel: Integrative Forschung zwischen Normativität und Unsicherheit. Campus, Frankfurt, Germany.

Petschel-Held, G., A. Block, M. Cassel-Gintz, J. Kropp, M. K. B. Lüdeke, O. Moldenhauer, F. Reusswig, and H. J. Schellnhuber. 
1999. Syndromes of global change: a qualitative modelling approach to assist global environmental management. Environmental Modeling and Assessment 4(4):295-314. https:// doi.org/10.1023/A:1019080704864

Poteete, A. R., M. A. Janssen, and E. Ostrom. 2010. Working together: collective action, the commons, and multiple methods in practice. Princeton University Press, Princeton, New Jersey, USA. https://doi.org/10.1515/9781400835157

Poteete, A. R., and E. Ostrom. 2008. Fifteen years of empirical research on collective action in natural resource management: struggling to build large- $\mathrm{N}$ databases based on qualitative research. World Development 36(1):176-195. https://doi. org/10.1016/j.worlddev.2007.02.012

Rindfuss, R. R., S. J. Walsh, B. L. Turner II, J. Fox, and V. Mishra. 2004. Developing a science of land change: challenges and methodological issues. Proceedings of the National Academy of Sciences 101(39):13976-13981. https://doi.org/10.1073/pnas.0401545101

Rist, S., M. Chiddambaranathan, C. Escobar, and U. Wiesmann. 2006. "It was hard to come to mutual understanding..."-The multidimensionality of social learning processes concerned with sustainable natural resource use in India, Africa and Latin America. Systemic Practice and Action Research 19(3):219-237. https://doi.org/10.1007/s11213-006-9014-8

Rudel, T. K. 2008. Meta-analyses of case studies: a method for studying regional and global environmental change. Global Environmental Change 18(1):18-25. https://doi.org/10.1016/j. gloenvcha.2007.06.001

Schellnhuber, H.-J., A. Block, M. Cassel-Gintz, J. Kropp, G. Lammel, W. Lass, R. Linienkamp, C. Loose, M. K. B. Lüdeke, O. Moldenhauer, G. Petschel-Held, M. Plöchl, and F. Reusswig. 1997. Syndromes of global change. Gaia 6(1):18-33. https://doi. org/10.14512/gaia.6.1.4

Schlager, E. 2007. A comparison of frameworks, theories, and models of policy processes. Pages 293-320 in P. A. Sabatier, editor. Theories of the policy process. Second edition. Westview Press, Boulder, Colorado, USA.

Scoones, I., R. Hall, S. M. Borras, B. White, and W. Wolford. 2013. The politics of evidence: methodologies for understanding the global land rush. Journal of Peasant Studies 40(3):469-483. https://doi.org/10.1080/03066150.2013.801341

Senge, P. M. 1990. The fifth discipline: the art \& practice of the learning organization. Doubleday/Currency, New York, New York, USA.

Sietz, D. 2014. Regionalisation of global insights into dryland vulnerability: better reflecting smallholders' vulnerability in northeast Brazil. Global Environmental Change 25:173-185. https://doi.org/10.1016/j.gloenvcha.2014.01.010

Sietz, D., S. E. M. Choque, and M. K. B. Lüdeke. 2012. Typical patterns of smallholder vulnerability to weather extremes with regard to food security in the Peruvian Altiplano. Regional Environmental Change 12(3):489-505. https://doi.org/10.1007/ $\underline{\text { s10113-011-0246-5 }}$

Sietz, D., M. K. B. Lüdeke, and C. Walther. 2011. Categorisation of typical vulnerability patterns in global drylands. Global
Environmental Change 21(2):431-440. https://doi.org/10.1016/j. gloenvcha.2010.11.005

Sietz, D., J. C. Ordoñez, M. T. J. Kok, P. Janssen, H. B. M. Hilderink, P. Tittonell, and H. van Dijk. 2017. Nested archetypes of vulnerability in African drylands: Where lies potential for sustainable agricultural intensification? Environmental Research Letters 12(9):095006. https://doi.org/10.1088/1748-9326/aa768b

Sietz, D., B. Untied, O. Walkenhorst, M. K. B. Lüdeke, G. Mertins, G. Petschel-Held, and H. J. Schellnhuber. 2006. Smallholder agriculture in northeast Brazil: assessing heterogeneous human-environmental dynamics. Regional Environmental Change 6(3):132-146. https://doi.org/10.1007/ s10113-005-0010-9

Srinivasan, V., E. F. Lambin, S. M. Gorelick, B. H. Thompson, and S. Rozelle. 2012. The nature and causes of the global water crisis: syndromes from a meta-analysis of coupled human-water studies. Water Resources Research 48(10):W10516. https://doi. org/10.1029/2011WR011087

Sterman, J. D. 2000. Business dynamics: systems thinking and modeling for a complex world. McGraw-Hill, Boston, USA.

Turner, B. L., M. Wuellner, T. Nichols, R. Gates, L. O. Tedeschi, and B. H. Dunn. 2017. A systems approach to forecast agricultural land transformation and soil environmental risk from economic, policy, and cultural scenarios in the north central United States (2012-2062). International Journal of Agricultural Sustainability 15(2):102-123. https://doi.org/10.1080/14735903.2017.1288029

Václavík, T., F. Langerwisch, M. Cotter, J. Fick, I. Häuser, S. Hotes, J. Kamp, J. Settele, J. H. Spangenberg, and R. Seppelt. 2016. Investigating potential transferability of place-based research in land system science. Environmental Research Letters 11(9):095002. https://doi.org/10.1088/1748-9326/11/9/095002

Václavík, T., S. Lautenbach, T. Kuemmerle, and R. Seppelt. 2013. Mapping global land system archetypes. Global Environmental Change 23(6):1637-1647. https://doi.org/10.1016/j.gloenvcha.2013.09.004

Van Asselen, S., and P. H. Verburg. 2012. A land system representation for global assessments and land-use modeling. Global Change Biology 18(10):3125-3148. https://doi.org/10.1111/ j.1365-2486.2012.02759.X

Van Vliet, J., N. R. Magliocca, B. Büchner, E. Cook, J. M. Rey Benayas, E. C. Ellis, A. Heinimann, E. Keys, T. M. Lee, J. Liu, O. Mertz, P. Meyfroidt, M. Moritz, C. Poeplau, B. E. Robinson, R. Seppelt, K. C. Seto, and P. H. Verburg. 2016. Meta-studies in land use science: current coverage and prospects. Ambio 45(1):15-28. https://doi.org/10.1007/s13280-015-0699-8

Van Vuuren, D. P., M. T. J. Kok, B. Girod, P. L. Lucas, and B. de Vries. 2012. Scenarios in global environmental assessments: key characteristics and lessons for future use. Global Environmental Change 22(4):884-895 https://doi.org/10.1016/j.gloenvcha.2012.06.001

Verburg, P. H., N. Crossman, E. C. Ellis, A. Heinimann, P. Hostert, O. Mertz, H. Nagendra, T. Sikor, K.-H. Erb, N. Golubiewski, R. Grau, M. Grove, S. Konaté, P. Meyfroidt, D. C. Parker, R. R. Chowdhury, H. Shibata, A. Thomson, and L. Zhen. 2015. Land system science and sustainable development of the earth system: a global land project perspective. Anthropocene 12:29-41. https://doi.org/10.1016/j.ancene.2015.09.004 
Vidal Merino, M., D. Sietz, F. Jost, and U. Berger. 2019. Archetypes of climate vulnerability: a mixed-method approach applied in the Peruvian Andes. Climate and Development, in press. https://doi.org/10.1080/17565529.2018.1442804

Wardropper, C. B., S. Gillon, A. S. Mase, E. A. McKinney, S. R. Carpenter, and A. R. Rissman. 2016. Local perspectives and global archetypes in scenario development. Ecology and Society 21(2):12. http://dx.doi.org/10.5751/ES-08384-210212

Weber, M. 1988. Die "Objektivität” sozialwissenschaftlicher und sozialpolitischer Erkenntnis. Pages 146-214 in Gesammelte Aufsätze zur Wissenschaftslehre. Mohr Siebeck, Tübingen, Germany.

Wolstenholme, E. F. 2003. Towards the definition and use of a core set of archetypal structures in system dynamics. System Dynamics Review 19(1):7-26. https://doi.org/10.1002/sdr.259

Wolstenholme, E. 2004. Using generic system archetypes to support thinking and modelling. System Dynamics Review 20 (4):341-356. https://doi.org/10.1002/sdr.302

Young, O. R., E. F. Lambin, F. Alcock, H. Haberl, S. I. Karlsson, W. J. McConnell, T. Myint, C. Pahl-Wostl, C. Polsky, P. S. Ramakrishnanm, H. Schroeder, M. Scouvart, and P. H. Verburg. 2006. A portfolio approach to analyzing complex humanenvironment interactions: institutions and land change. Ecology and Society 11(2):31. https://doi.org/10.5751/ES-01799-110231 
Appendix 1: Studies included in the systematic literature review.

Alford, K., S. Cork, J. Finnigan, N. Grigg, B. Fulton, and M. Raupauch. 2014. The challenges of living scenarios for Australia in 2050. Journal of Futures Studies 18(3):115-126.

Araneo, P. 2017. Re-imagining cultural heritage archetypes towards sustainable futures. Journal of Futures Studies 21(4):37-50.

Banson, K. E., N. C. Nguyen, and O. J. Bosch. 2016. Using system archetypes to identify drivers and barriers for sustainable agriculture in Africa: A case study in Ghana. Systems Research and Behavioral Science 33(1):79-99.

Barnes, R. A. 2013. The capacity of property rights to accommodate social-ecological resilience. Ecology and Society 18(1):6. http://dx.doi.org/10.5751/ES-05292-180106

Beers, P. J. and B. van Mierlo. 2017. Reflexivity and Learning in System Innovation Processes. Sociologia Ruralis 57(3):415-436.

Bina, O. and A. Ricci. 2016. Exploring participatory scenario and storyline building for sustainable urban futures - the case of China in 2050. Foresight 18(5):509-534.

Bocken, N. M., S. W. Short, P. Rana, and S. Evans. 2014. A literature and practice review to develop sustainable business model archetypes. Journal of Cleaner Production 65:42-56.

Bohnsack, R., J. Pinkse, and A. Kolk. 2014. Business models for sustainable technologies: Exploring business model evolution in the case of electric vehicles. Research Policy 43(2):284-300.

Brzezina, N., K. Biely, A. Helfgott, B. Kopainsky, J. Vervoort, and E. Mathijs. 2017. Development of organic farming in Europe at the crossroads: Looking for the way forward through system archetypes lenses. Sustainability 9(5):821.

Butcher, J. B., D. Nover, T. E. Johnson, C. M. Clark. 2015. Sensitivity of lake thermal and mixing dynamics to climate change. Climatic Change 129(1-2):295-305.

Cullum, C., G. Brierley, G. L. Perry, and E. T. Witkowski. 2017. Landscape archetypes for ecological classification and mapping: The virtue of vagueness. Progress in Physical Geography 41(1):95-123.

Cullum, C., K. H. Rogers, G. Brierley, and E. T. Witkowski. 2016. Ecological classification and mapping for landscape management and science: Foundations for the description of patterns and processes. Progress in Physical Geography 40(1):38-65.

Dangerman, A. T. C. J. and H. J. Schellnhuber. 2013. Energy systems transformation. Proceedings of the National Academy of Sciences of the United States of America 110(7):E549-E558.

Eisenack, K. 2012. Archetypes of adaptation to climate change. In: Glaser, M., G. Krause, B.M.W. Ratter, and M. Welp (eds.) Human/Nature Interactions in the Anthropocene: Potentials of Social-Ecological Systems Analysis. Routledge, New York, NJ, pp. 107-122.

Eisenack, K., M. Lüdeke, and J. Kropp. 2006. Construction of archetypes as a formal method to analyze social-ecological systems. In: Proceedings of the Institutional Dimensions of Global Environmental Change Synthesis Conference. Bali (Vol. 6, No. 9, December 2006).

Emili, S., F. Ceschin, and D. Harrison. 2016. Product-service system applied to distributed renewable energy: A classification system, 15 archetypal models and a strategic design tool. Energy for Sustainable Development 32:71-98. 
Felgenhauer, T. 2015. Addressing the limits to adaptation across four damage-response systems. Environmental Science \& Policy 50:214-224.

Fischer, J., D. J. Abson, A. Bergsten, N. F. Collier, I. Dorresteijn, J. Hanspach, K. Hylander, J. Schultner, and F. Senbeta. 2017. Reframing the Food-Biodiversity Challenge. Trends in Ecology \& Evolution 32(5):335-345.

Gerst, M. D., M. E. Cox, K. A. Locke, M. Laser, and A. R. Kapuscinski. 2014. A taxonomic framework for assessing governance challenges and environmental effects of integrated food-energy systems. Environmental Science \& Technology 49(2):734-741.

Hill, J., M. Stellmes, T. Udelhoven, A. Röder, and S. Sommer. 2008. Mediterranean desertification and land degradation: mapping related land use change syndromes based on satellite observations. Global and Planetary Change 64(3-4):146-157.

Hunt, D. V. L., D. R. Lombardi, S. Atkinson, A. R. G. Barber, M. Barnes, C. T. Boyko, J. Brown, J. Bryson, D. Butler, S. Caputo, M. Caserio, R. Coles, R. F. D. Cooper, R. Farmani, M. Gaterell, J. Hale, C. Hales, C. N. Hewitt, L. Jankovic, I. Jefferson, J. Leach, A. R. MacKenzie, F. A. Memon, J. P. Sadler, C. Weingaertner, J. D. Whyatt, and C. D. F. Rogers. 2012. Scenario archetypes: converging rather than diverging themes. Sustainability 4(4):740-772.

Jäger, J., M. D. A. Rounsevell, P. A. Harrison, I. Omann, R. Dunford, M. Kammerlander, and G. Pataki. 2015. Assessing policy robustness of climate change adaptation measures across sectors and scenarios. Climatic Change 128(3-4):395-407.

Kubiszewski, I., S. J. Anderson, R. Costanza, and P. C. Sutton. 2016. The future of ecosystem services in Asia and the Pacific. Asia \& the Pacific Policy Studies 3(3):389-404.

Kummu, M., J. H. A. Guillaume, H. De Moel, S. Eisner, M. Flörke, M. Porkka, S. Siebert, T. I. E. Veldkamp, and P. J. Ward. 2016. The world's road to water scarcity: shortage and stress in the 20th century and pathways towards sustainability. Scientific Reports 6:38495.

Lee, H., and S. Lautenbach. 2016. A quantitative review of relationships between ecosystem services. Ecological Indicators 66:340-351.

Levers, C., D. Müller, K. Erb, H. Haberl, M. R. Jepsen, M. J. Metzger, P. Meyfroidt, T. Plieninger, C. Plutzar, J. Stürck, P.H., P. J. Verkerk, and T. Kuemmerle. 2018. Archetypical patterns and trajectories of land systems in Europe. Regional Environmental Change 18:715-732.

Li, S. S., M. C. Boudreau, M. Huber, and R. T. Watson. 2013. Sustainability performance and CSR disclosure: the missing link. International Journal of Social Ecology and Sustainable Development 4(2):34-47.

Lim-Camacho, L., A. Ariyawardana, G. K. Lewis, S. J. Crimp, S. Somogyi, B. Ridoutt, and S. M. Howden. 2017. Climate adaptation of food value chains: the implications of varying consumer acceptance. Regional Environmental Change 17(1):93-103.

Locatelli, B., S. Lavorel, S. Sloan, U. Tappeiner, and D. Geneletti. 2017. Characteristic trajectories of ecosystem services in mountains. Frontiers in Ecology and the Environment 15(3):150-159.

Lopez, S. R., T. S. Hogue, and E. D. Stein. 2013. A framework for evaluating regional hydrologic sensitivity to climate change using archetypal watershed modeling. Hydrology and Earth System Sciences 17(8):3077. 
Luederitz, C., D. J. Abson, R. Audet, and D. J. Lang. 2017. Many pathways toward sustainability: Not conflict but co-learning between transition narratives. Sustainability Science 12(3):393-407.

Maury, O., L. Campling, H. Arrizabalaga, O. Aumont, L. Bopp, G. Merino, D. Squires, W. Cheungi, M. Goujon, C. Guivarch, S. Lefort, F. Marsac, P. Monteagudo, R. Murtugudde, H. Österblom, J. F. Pulvenis, Y. Ye, and B. J. van Ruijven. 2017. From shared socioeconomic pathways (SSPs) to oceanic system pathways (OSPs): Building policy-relevant scenarios for global oceanic ecosystems and fisheries. Global Environmental Change 45:203-216.

Messerli, P., A. Peeters, O. Schoenweger, V. Nanhthavong, and A. Heinimann. 2015. Marginal land or marginal people? Analysing patterns and processes of large-scale land acquisitions in South-East Asia. International Development Policy 6:136-171.

Mirchi, A., D. W. Watkins, C. J. Huckins, K. Madani, and P. Hjorth. 2014. Water resources management in a homogenizing world: Averting the Growth and Underinvestment trajectory. Water Resources Research 50(9):7515-7526.

Mokhtar, A. and S. Aram. 2017. Systemic insights into agricultural groundwater management: case of Firuzabad Plain, Iran. Water Policy 19(5):867-885.

Moore, J. 2015. Ecological footprints and lifestyle archetypes: exploring dimensions of consumption and the transformation needed to achieve urban sustainability. Sustainability 7(4):4747-4763.

Moraine, M., M. Duru, and O. Therond. 2017. A social-ecological framework for analyzing and designing integrated crop-livestock systems from farm to territory levels. Renewable Agriculture and Food Systems 32(1):43-56.

Oberlack, C. 2017. Diagnosing institutional barriers and opportunities for adaptation to climate change. Mitigation and Adaptation Strategies for Global Change 22(5):805-838.

Oberlack, C., and K. Eisenack. 2014. Alleviating barriers to urban climate change adaptation through international cooperation. Global Environmental Change 24:349-362.

Oberlack C., and K. Eisenack. 2017. Archetypical barriers to climate change adaptation. Journal of Institutional Economics (online first), doi: 10.1017/S1744137417000509.

Oberlack, C., L. Tejada, P. Messerli, S. Rist, and M. Giger. 2016. Sustainable livelihoods in the global land rush? Archetypes of livelihood vulnerability and sustainability potentials. Global Environmental Change 41:153-171.

Saqalli, M., B. Gérard, C. Bielders, and P. Defourny. 2010. Testing the impact of social forces on the evolution of Sahelian farming systems: A combined agent-based modeling and anthropological approach. Ecological Modelling 221(22):2714-2727.

Sharif, A. M., and Z. Irani. 2016. People, process and policy perspectives on food security: an exploration using systems archetypes. Transforming Government- People Process and Policy 10(3):359-367.

Sietz, D., J. C. Ordoñez, M. T. J. Kok, P. Janssen, H. B. Hilderink, P. Tittonell, and H. van Dijk. 2017. Nested archetypes of vulnerability in African drylands: where lies potential for sustainable agricultural intensification?. Environmental Research Letters 12(9):095006.

Tukker, A., and M. Butter. 2007. Governance of sustainable transitions: about the 4(0) ways to change the world. Journal of Cleaner Production 15(1):94-103. 
Turner, B. L., M. Wuellner, T. Nichols, R. Gates, L. O. Tedeschi, and B. H. Dunn. 2017. A systems approach to forecast agricultural land transformation and soil environmental risk from economic, policy, and cultural scenarios in the north central United States (20122062). International Journal of Agricultural Sustainability 15(2):102-123.

UNEP (2007), Global Environmental Outlook 4. United Nations Environment Programme. Progress Press, Valetta, Malta.

Václavík, T., F. Langerwisch, M. Cotter, J. Fick, I. Häuser, S. Hotes, J. Kamp, J. Settele, J. H. Spangenberg, and R. Seppelt. 2016. Investigating potential transferability of place-based research in land system science. Environmental Research Letters, 11(9):095002.

Václavík, T., S. Lautenbach, T. Kuemmerle, and R. Seppelt. 2013. Mapping global land system archetypes. Global Environmental Change 23(6):1637-1647.

Vidal Merino, M., D. Sietz, F. Jost, and U. Berger. 2018. Archetypes of climate vulnerability: a mixed-method approach applied in the Peruvian Andes. Climate and Development, 1-17. (in press), doi: 10.1080/17565529.2018.1442804.

Weissteiner, C. J., M. Boschetti, K. Böttcher, P. Carrara, G. Bordogna, and P. A. Brivio. 2011. Spatial explicit assessment of rural land abandonment in the Mediterranean area. Global and Planetary Change 79(1-2):20-36.

Whitelaw, P. A., B. E. King, and D. Tolkach. 2014. Protected areas, conservation and tourismfinancing the sustainable dream. Journal of Sustainable Tourism 22(4):584-603.

Worman, C. O. D. 2010. Trooping fairies, trolls, and talking tigers: the influence of traditional wilderness archetypes on current land use patterns. Biodiversity and Conservation 19(11):3171-3193. 